\title{
PLEOMORPHIC ADENOMA PALATE: A RARE CASE
}

\author{
Faiz Muqtadir' ${ }^{1}$, Anil Doddamani², Khalid Gufran³ ${ }^{3}$ Shireen Rokadia ${ }^{4}$
}

\section{HOW TO CITE THIS ARTICLE:}

Faiz Muqtadir, Anil Doddamani, Khalid Gufran, Shireen Rokadia. "Pleomorphic Adenoma Palate: A Rare Case". Journal of Evolution of Medical and Dental Sciences 2015; Vol. 4, Issue 20, March 09; Page: 3544-3547,

DOI: $10.14260 /$ jemds $/ 2015 / 510$

ABSTRACT: Pleomorphic adenoma (PA) is the most common benign mixed salivary gland neoplasm that accounts for $60 \%$ of all benign salivary gland tumors. It has diverse histological presentation and occurs in both major and minor salivary glands. PA of minor salivary gland in the palate is a common entity. We report the case of a 60 -year-old female who presented with a painless slow growing swelling of palate over the last 2 years. The mass was crossing the midline of the soft palate. Fine needle aspiration cytology (FNAC) was suggestive of PA. The entire tumor mass was excised along with overlying mucosa. Histopathological examination confirmed diagnosis of PA of minor salivary gland. There has been no recurrence of the lesion since 6 months.

KEYWORDS: pleomorphic adenoma, mixed salivary gland neoplasm, soft palate swelling, benign salivary gland tumours.

INTRODUCTION: Pleomorphic adenoma (PA) is the most common tumor $(60 \%)$ of major and minor salivary glands, nearly $70 \%$ of the tumors of minor salivary glands are PAs, and the most common intraoral site is the palate, followed by upper lip and buccal mucosa. [1] Studies have reported that in world population $13.9-51.4 \%$ of all salivary gland tumors arise from an intraoral site and 34.7-67.1\% of them are benign. ${ }^{[2]}$ This is a tumor of diverse histological and topographical presentation. The differential diagnoses are many and atypical presentations of this tumor are not uncommon. The importance of lesions lies in the fact that they are more likely to be malignant when associated with minor salivary glands (50\%). [3] Benign tumor, though has the potential to attain huge size, generally is a symptom-free mass. Fine needle aspiration (FNA) is a sensitive and specific diagnostic tool for determining severity of neoplasm as well as to identify histological subtype. The aim of this case report is to present histopathologically diagnosed PA of palate in a 60 year-old female, to emphasize its peculiar nature of growing slowly for over 2 years to a size of $5 \times 4 \mathrm{~cm}$, and yet asymptomatic. It can be misdiagnosed as malignant tumor on blind clinical diagnosis, and hence this presentation also emphasizes on the need for awareness of its diverse presentation by the examining clinician that could influence the outcome greatly and for histopathological diagnosis of such growth before any definitive treatment.

CASE REPORT: A 60-year-old female presented with a slow growing swelling, of approximately 2 years duration involving her soft palate on right side. The lesion always had been asymptomatic, with no associated pain or paresthesia. The patient's medical history was non-contributory. She had no known allergies and had not undergone any surgeries of head and neck. She had no complaints of pharyngeal or airway obstruction. General physical examination revealed a well oriented and moderately built individual with no signs of any systemic illness. The patient presented a typical 'hot potato in mouth' speech. The clinical examination revealed nonulcerated, dome-shaped, palatal swelling on soft palate crossing the midline [Figure 1]. The mass was smooth surfaced and overlying mucosa was red and stretched. The lesion was firm, and nontender on palpation. 


\section{CASE REPORT}

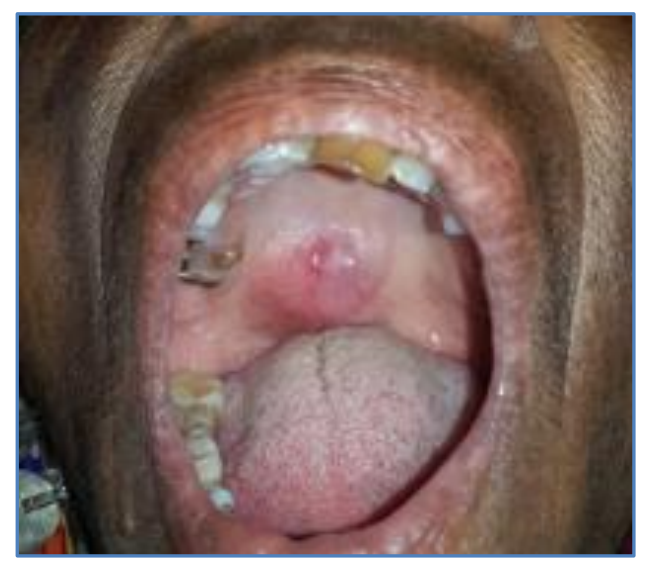

\section{Figure 1}

FNA biopsy was performed, which was suggestive of PA. All preoperative blood and urine investigations were done, which were within normal limits. The patient was operated for wide local excision of the mass and primary closure of adjacent mucosa. The excised mass was $5 \times 4 \mathrm{~cm}$ [Figure 2]. Following excision of tumor, surgical wound [Figure 3] was closed in layers in a tensionfree water tight fashion.

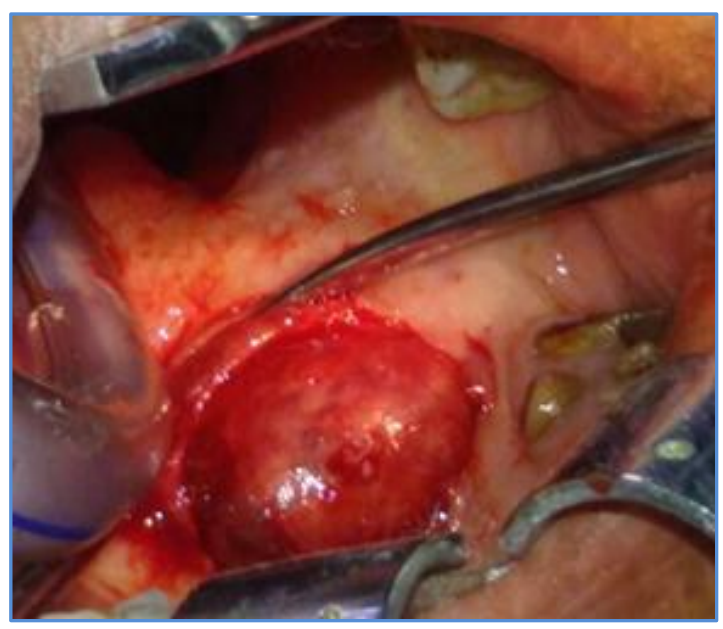

Figure 2

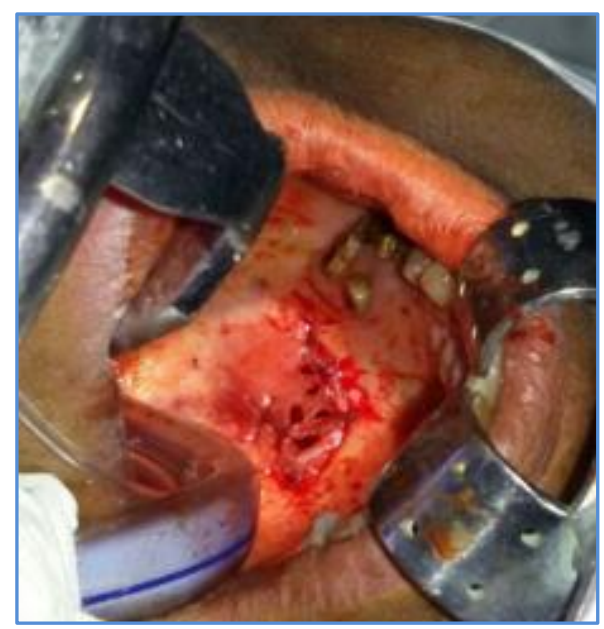

Figure 3

The excised mass was sent for histopathological examination[Figure 4], which revealed stratified squamous epithelium covering connective tissue and underlying connective tissue showed the cells arranged in sheets and duct-like pattern with a mucoid background [Figure 5]. This was confirmatory of PA. The patient's postoperative course was uneventful. The healing was satisfactory. No recurrence was observed after a follow-up period of 6 months. 


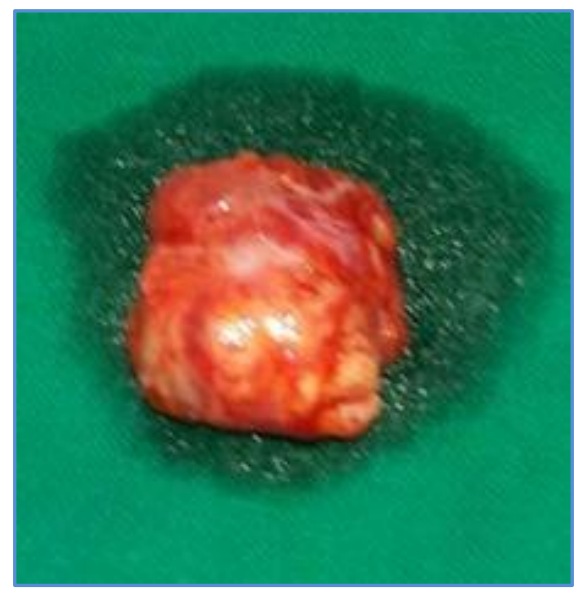

Figure 4

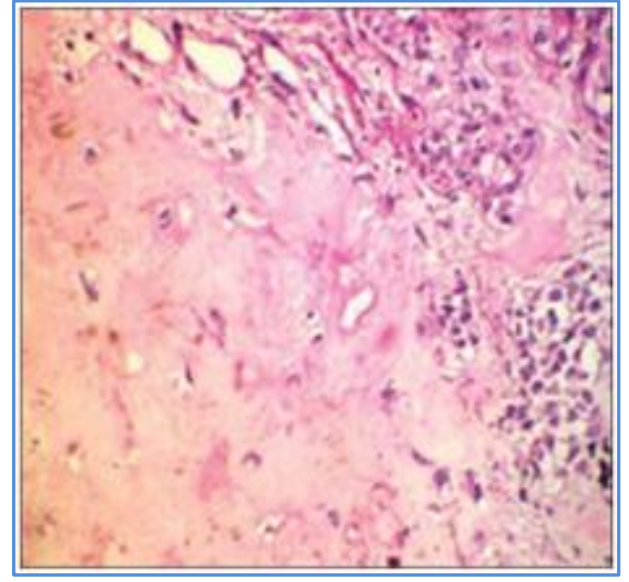

Figure 5

DISCUSSION: PA of minor salivary gland is most common in palate (10\%), followed by lip (4\%).[4] The unusual sites are sinuses, larynx epiglottis, and trachea. PAs have also been reported in tongue,[5] soft palate, ${ }^{[3]}$ uvula, ${ }^{[6]}$ and even external auditory canal.[7] Though the case we presented is not a rare one, these kinds of tumor are most often malignant and are often misdiagnosed. Clinically the patient presented a solitary, painless, slow growing, well-circumscribed palatal lump which is typical presentation of such tumor. The mechanical symptoms most commonly manifested by tumors of this location are dyspnea, dysphagia, acute airway obstruction, and obstructive sleep apnea.[8] In our case the presenting complaints were dysphagia and difficulty in speech. Surprisingly a tumor of $7 \times 6 \mathrm{~cm}$ in size did not produce any respiratory distress.

The main diagnostic modalities are FNA biopsy and imaging. Cytological finding in PA are typically of mixed epithelial cells and mesenchymal elements. These features were clearly illustrated in our case. The histopathological confirmation is mandatory in operating these tumors. However, differentiation from adenoid cystic carcinoma and polymorphous low grade adenocarcinoma may be difficult with FNA alone. ${ }^{[9]}$ Imaging with ultrasound, MRI, or computed tomography (CT) may be used depending on the site and size of tumor.[10]

Surgical excision is the treatment of choice. Longevity and recurrence are risk factors for malignant transformation. The propensity for malignant transformation is documented to be 1.923.3\%.[11] The primary goal of excision should be complete removal of mass without risking recurrence. We performed complete excision of tumor with overlying mucosa and surgical wound was closed with advancement of adjacent mucosa. This produced an excellent result. The excised region can be left to heal by secondary intention also. In this case the tumor itself served as tissue expander, to advance adequate mucosal coverage, and achieve primary healing.

SUMMARY AND CONCLUSION: PA, though a common entity, is still a challenging tumor for pathologist, radiologist, and the surgeon. Its diverse histological and topographical property makes the tumor special. The examining clinician and treating surgeon must be aware of its recurrence, longevity, and malignant potential if incorrectly diagnosed or treated. 


\section{REFERENCES:}

1. Sreenivas DS. Pleomorphic adenoma of the palate: A case report. J Indian Dent Assoc 2011; 5: 557-8.

2. Wang D, Li Y, He H, Liu L, Wu L, He Z. Intraoral minor salivary gland tumours in a Chinese population: A retrospective study on 737 cases. Oral Surg Oral Med Oral Pathol Oral Radiol Endod 2007; 104: 94-100.

3. Daryani D, Gopakumar R, Ajila V. Pleomorphic adenoma of soft palate: Myoepithelial cell predominant. Indian J Dent Res 2011; 22: 853-6.

4. Ellis GL, Auclair PL. Tumours of the Salivary Glands, Atlas of Tumour Pathology. 3 rd series, Facsicle 17. Washington: Armed Forces Institute of Pathology; 1996. Ghosh SK, Saha J, Chandra S, Datta S. Pleomorphic adenoma of the base of the tongue: A case report. Indian J Otolaryngol Head Neck Surg 2011; 63: 113-4.

5. Su A, Apple SK, Moatamed NA. Pleomorphic adenoma of the vulva, clinical reminder of a rare occurrence. Rare Tumours 2012; 4: e16.

6. Koyuncu M, Karagoz F, Kiliacarslan H. Pleomorphic adenoma of the external auditory canal. Eur Arch Otorhinolaryngol 2005; 262: 969-71.

7. Yoshihara T, Suzuki S. Pleomorphic adenoma of tongue base causing dysphagia and dyspnoea. J Laryngol Otol 2000; 114: 793-5.

8. Das D, Anim JT. Pleomorphic adenoma of the salivary gland: To what extent does fine needle aspiration cytology reflect histopathological features? Cytopathology 2005; 16: 65-70.

9. Lingam RK, Daghir AA, Nigar E, Abbas SA, Kumar M. Pleomorphic adenoma (benign mixed tumour) of the salivary glands: Its diverse clinical, radiological, and histopathological presenation. Br J Oral Maxillofac Surg 2011; 49: 14-20.

10. Ethunandan M, Witton R, Hoffman G, Spedding A, Brennan PA. Atypical features in pleomorphic adenoma: A clinicopathological study and implication for management. Int J Oral Maxillofac Surg 2006; 35: 608-12.

\section{AUTHORS:}

1. Faiz Muqtadir

2. Anil Doddamani

3. Khalid Gufran

4. Shireen Rokadia

\section{PARTICULARS OF CONTRIBUTORS:}

1. Senior Resident, Department of ENT, ESICMC, Gulbarga.

2. Professor, Department of ENT, ESICMC, Gulbarga.

3. Lecturer, Department of Periodontics, Salman Bin Abdul Aziz University, Al Kharj, KSA.

FINANCIAL OR OTHER COMPETING INTERESTS: None
4. Assistant Professor, Department of Ophthalmology, Saptagiri Medical College, Bangalore.

NAME ADDRESS EMAIL ID OF THE CORRESPONDING AUTHOR:

Dr. Faiz Muqtadir, \# 5-408/106/10,

Islamabad Colony, Gulbarga-585104.

E-mail: drfaiz.muqtadir@gmail.com

Date of Submission: 07/02/2015.

Date of Peer Review: 08/02/2015.

Date of Acceptance: 26/02/2015.

Date of Publishing: 09/03/2015. 